\title{
The health and social impact of Blood Donors Associations: A Social Return on Investment (SROI) analysis
}

\section{Elisa Ricciuti, Maria Vittoria Bufali}

\section{ABSTRACT}

Although research on blood donation abounds, no studies have yet attempted to estimate the socio-economic value generated from Blood Donors Associations (BDAs).

To fill this gap, the authors ran a Social Return on Investment (SROI) analysis on four units of the largest BDA in Italy, the Association of Voluntary Italian Blood Donors ("Avis"). This study used multiple methods for data collection and analysis. A systematic literature review helped the identification of proper financial proxies to highlight the economic value of the social and health impacts experienced by Avis members. A focus group with key informants gathered their views on the areas of impact selected for the analysis: early detection of diseases, adoption of healthier lifestyles, social capital, human capital, personal satisfaction and reinforcement of a 'giving culture'.

Primary data collection involved (a) an Activity Based Costing analysis (b) a self-reported questionnaire to 1.066 BDA members and unassociated donors enabling the comparison of the blood donation experience of these two groups. The SROI analysis resulted in four positive ratios, varying between $€ 1.70$ and $€ 13.80$.

This study contributes to the knowledge on impact evaluations in TSOs. Policy implications refer to BDAs deserving financial and material support for their capacity to generate positive social impacts.

\section{KEY WORDS}


Social Return on Investment (SROI); Social Impact Evaluation; Blood Donors Associations; Blood donation; Third Sector.

\section{INTRODUCTION AND RESEARCH GAPS}

Blood donation has been a popular topic in the socio-economic literature through the development of at least three streams of research. First, research devoted to the analysis of the so-called "healthy donor effect" has investigated how blood donation relates to health outcomes experienced by donors. It has sought to understand if blood donation represents a determinant of a better health status or, conversely, if the latter is simply a result of the screenings implemented while assessing the eligibility of donors (Shehu et al., 2015; Gallerani et al., 2014; Atsma et al., 2011).

Second, a plethora of studies has addressed the implications of the ever-increasing shortages in blood supply faced by national blood systems in different countries. From this perspective, the achievement of a deeper understanding of the motives that spur blood donors' willingness to donate is considered an essential step to maintain the selfsufficiency of national blood systems (Roberts and Wolkoff, 1988; Karacan et al., 2013; lajya et al., 2013). Consequently, the effectiveness of the recruitment and retention strategies of Blood Collection Agencies (BCAs) and/or Blood Donors Associations (BDAs) becomes a fundamental driver for donation (Chliaoutakis et al., 1994; Hinrichs et al., 2008). While a considerable amount of research has investigated blood donors' motivating factors (Nilsson Sojka and Sojka, 2003; Bani and Strepparava, 2011; Evans and Ferguson, 2014; Guiddi et al., 2015; Alfieri et al., 2016), most studies in this field provided empirical evidence about the relative incidence of key drivers on the individual decisionmaking process leading to donation (Gillespie and Hillyer, 2002; Masser et al., 2008; 
Boenigk et al., 2011; Bednall et al., 2013; Ferguson, 2015), leaving a research gap in the estimation of benefits based on monetary values or in the calculation of the socioeconomic value generated by BDAs' activities.

Third, the health economics literature has given several contributions to the field, through the application of economic evaluations to the study of blood donation. However, economic evaluations focus on specific aspects of the blood supply chain - such the suitability of alternative screening strategies for eligibility assessments (Sarov et al., 2007; Fischinger et al., 2010) or of autologous donation (Lee et al., 1997), and have not yet assessed the overall blood donation experience or the role played by BDAs in the generation of incremental value to the benefit of their members (terms that will be used hereafter to identify blood donors and/or volunteers belonging to a BDA).

This gap exists even in the social science literature and Social Impact Evaluations (SIEs) in particular. Far from representing a 'newcomer' in nonprofit studies, this stream of literature results from the deep-rooted necessity for Third Sector Organizations (TSOs) to provide evidence of the effectiveness of their activities in addressing social needs, and their efficient resource use (Harlock, 2013). Consequently, a growing number of TSOs are accepting the challenge of impact measurement (Ógáin et al., 2012). This tool is functional from multiple perspectives, including performance management and resource allocation, people- and fund-raising strategies, communication, and accountability towards stakeholders (Harlock, 2013; Arvidson et al., 2013; Maier et al., 2015).

Because of this gap in the current knowledge, the authors sought to run an empirical evaluation of the impacts experienced by blood donors and volunteers who are members of a TSO like a BDA, both on the health and wellbeing of the donor and volunteer and on the social and relational sphere. Thus, the research question driving the study is: does the 
existence of a BDA generate a positive and desirable socio-economic value to its members?

To address this question, a Social Return on Investment (SROI) analysis was performed, consisting of a financial assessment of socio-economic value to compare "a project's net benefits to the investment required to generate those benefits over a certain period of time" (Emerson and Cabaj, 2000, p. 11). More specifically, a retrospective analysis was performed through an "evaluative" SROI (Nicholls et al., 2012, p. 8), with an annual time horizon (data refer to 2014, the most recent year with complete and reliable data in the Avis database). The applied formula is as follows:

\section{Present Value of impacts $\mathrm{t}-$ Value of inputs $\mathrm{t}$ \\ Net SROI $t=$ Value of inputs $t$}

In other words, SROI "tells the story of how change is being created by measuring social, environmental and economic outcomes and uses monetary values to represent them" (Nicholls et al., 2012, p. 8) in such a way that the resulting ratio provides a synthetic representation of the value generated for each euro invested in the evaluated project.

The value of this methodological choice is twofold. First, while a long tradition of established evaluation methods exists in health and healthcare, including, among others, Cost-Benefit Analysis, Cost-Effectiveness Analysis and Cost-Utility Analysis (Drummond et al., 2015), recent studies have reported a relatively low usage of the SROI methodology in the health sector (Millar and Hall, 2013; Banke-Thomas et al., 2015) and particularly in the field of blood donation. Thus, this study contributes to the blood donation literature by delivering a SROI analysis in a severely understudied field. Second, SROI is a suitable method to achieve a concise and highly intuitive measure of costs and benefits while simultaneously allowing a proper degree of stakeholder engagement (Arvidson et al., 
2010; Arvidson et al., 2013; Simsa et al., 2014) and performance evaluation (Cordes, 2016). Therefore, this study also nurtures the literature on SIE by proposing a method for evaluating the social benefits of TSOs, which is a highly debated topic in both academia and policy-making, but still lacking robust evidence to date.

Italy is a perfect case study because of the specific characteristics of the country's blood system configuration and due to the normative shifts affecting its Third Sector development. On the one hand, although the Italian blood system is coordinated by the Italian National Health Service (NHS) (as in the UK, France and Ireland), a significant share of blood collection activities is managed by a TSO called Avis ("Associazione Volontari Italiani del Sangue", Association of Voluntary Italian Blood Donors), the largest BDA in the country by far, covering $75.17 \%$ of all Italian blood donors in 2014 (Bufali et al., 2017). For this reason, Healy defined the Italian system a "community blood bank model" (2000, p. 1640). However, unlike countries such as Germany and Belgium, where the Red Cross can claim a near-monopoly on blood collection, Italy is experiencing a sort of duopoly formed by privately- and publicly-run BCAs, similar to Spain (Cavazza and Jommi, 2013). On the other hand, the debate on SIE has recently acquired an enormous salience in Italy, as it is highly connected with the recent Reform of the Third Sector (Law 106/2016), approved after a long gestation in July 2016, which heightens the need for TSOs to provide evidence of their ability to generate positive impacts on the community. For all these reasons, Italy is now a fertile ground for experimentation.

\section{RESEARCH DESIGN AND METHODS}

This is a pilot study that uses the following multiple methods for data collection and analysis (Table 1). 
Table 1: Research stages, aims and methods

\begin{tabular}{|c|c|c|}
\hline STAGES & AIM & METHOD \\
\hline \multirow{2}{*}{ EXPLORATION } & $\begin{array}{l}\text { Background on method (SROI) and financial } \\
\text { proxies }\end{array}$ & Systematic literature review \\
\hline & Identification of pilot units & Sampling \\
\hline \multirow{3}{*}{$\begin{array}{l}\text { DATA } \\
\text { COLLECTION }\end{array}$} & $\begin{array}{l}\text { Identification and decision on the areas of } \\
\text { impact }\end{array}$ & Focus group \\
\hline & Quantification of inputs & $\begin{array}{l}\text { Review and re-classification of } \\
\text { balance sheets }\end{array}$ \\
\hline & Quantification of benefits & Survey \\
\hline \multirow{3}{*}{$\begin{array}{l}\text { DATA ANALYSIS } \\
\text { (SROI ANALYSIS) }\end{array}$} & $\begin{array}{l}\text { Cost analysis and valorization of non- } \\
\text { monetized inputs }\end{array}$ & Activity Based Costing (ABC) Analysis \\
\hline & Monetization of the benefits & $\begin{array}{l}\text { Application of proxies to survey } \\
\text { results }\end{array}$ \\
\hline & SROI ratios & Application of SROI formula \\
\hline
\end{tabular}

\section{Stage I - Exploration}

\section{Systematic literature review}

A systematic literature review investigated the contributions of previous economic evaluations of the socio-economic value provided by BCAs or BDAs (Figure 1). It aimed to provide exhaustive coverage of studies with at least one of the following focuses: economic evaluations based on the monetization of the impacts experienced by blood donors; the motivating factors influencing blood donation or, more broadly, prosocial 
behaviors; and/or the methodological guidelines concerning the use of SROI to account for the impacts of health interventions. The authors collected both published and "grey" literature, including doctoral theses and institutional reports. Peer-reviewed articles and dissertations were extracted from Scopus, Medline, Web of Science and Ethos, plus directly sourced from relevant journals (Social Science and Medicine, The Lancet, Nonprofit and Voluntary Sector Quarterly). The choice of databases and journals reflected the multidisciplinary angle of the study by addressing both health and nonprofit studies. Search strategies were as follows: "social return on investment" AND/OR "blood donation", in combination with: (social impact*); (social impact ${ }^{\star}$ ) AND (nonprofit); (social return on investment OR cost-benefit analysis); (association*) AND (social capital); (association*) AND (CBA); (cost-benefit analysis) AND (social impact*); (human capital) AND (social capital) AND (self-esteem). Furthermore, sources were searched on PubMed and Google Scholar for suggested articles labelled as "similar" to the previous ones, and on specific repositories of organizations related to the topic, i.e. Social Value UK for the use of SIE methods.

In total 1,395 studies were yielded for possible inclusion. A screening of the titles and abstracts revealed two types of contributions to be excluded:

1) Economic evaluations focused only on specific phases of blood donation or not based on benefit monetization (other than CBA and SROI), or focused on actors other than blood donors;

2) SROI reports not focused on blood donation, or SROI methodological guidelines not focused on health impacts.

Once removed duplicates, 31 papers were assessed as potentially relevant and, after a screening of their reference lists, 6 articles were added. 
The authors independently analyzed each study and entered the relevant information into an electronic coding form, before meeting to compare their findings and resolve inconsistencies through discussion. Agreement was reached on the lack of economic appraisals estimating the full socio-economic value provided by BCAs or BDAs. The review supported the development of a cross-validated set of categories representing the social and health impacts pursued by blood donors. This would form the basis of an exploration of the financial proxies capable of providing a monetary expression of the benefits to be included in the SROI analysis.

\section{[Figure 1 - The systematic literature review process]}

\section{Sampling}

This pilot study involved the selection of a narrow sample of Avis units (4) with the aim of ensuring an acceptable level of coherence with the structural and organizational features of Avis. The number is far from being representative of the Avis units scattered through the country, but still consistent with a pilot in-depth study, able to offer suggestions and uncover limitations for potential replicability. The authors built the ideal sample according to three selection criteria: (a) organizational model; (b) geographical location; and (c) size (i.e., the annual volumes of bags of whole blood and blood components collected).

Organizational model: the ideal units operate at the municipal level and are distinctive in that BDAs oversee the simultaneous management of the following three activities: blood donors' recruitment and retention, blood collection and activities related to raising awareness and promoting blood donation. This strategic choice was based on two considerations. First, this model is the most widespread configuration adopted by BDAs in Italy (representing, in $2014,71 \%$ of the cases in which Avis directly manage blood 
collection activities, and $36 \%$ of all BCAs operating in the country (Bufali et al., 2017).

Second, the fact that the three activities are carried out by one unit allow the researchers to directly correlate the impacts experienced by members with the entire spectrum of inputs and costs involved in carrying out these activities.

Geographic location: the ideal sample reflects the relative presence of the selected organizational model in the country (Table 2).

Table 2: AVIS organizational model's diffusion in the country

\begin{tabular}{lll}
\hline & $\begin{array}{c}\text { Model's } \\
\text { diffusion }\end{array}$ & $\begin{array}{l}\text { Units to } \\
\text { be included }\end{array}$ \\
\hline NORTH & $42,58 \%$ & 2,1 \\
CENTRE & $25,16 \%$ & 1,3 \\
SOUTH & $32,26 \%$ & 1,6 \\
\hline
\end{tabular}

Size: the ideal sample includes both medium-sized and large units in terms of volumes of blood collection. The size has implications in terms of economies of scale and economic efficiency gains. Also, this variable may exert a controversial influence with respect to the scope of impacts (in larger BDAs, a higher number of members can be positively affected) and the intensity of impacts (a wider membership may result in a weaker relational component implied in the donation experience).

Taking all these criteria into consideration, the ideal sample was formed by 5 units, which received a formal request to participate in the study. Although all the units agreed to participate, one unit lacked a comprehensive mailing list of its donors, an essential asset for the submission of the online survey. Due to this constraint, the unit was excluded from the analysis. Thus, the final sample for the pilot study consisted of 4 units (Table 3 ). From here onwards, the units are designated by progressive Greek letters, to respect the anonymity of respondents as indicated in the research's Informed Consent form (details below). 
Table 3: The sample of units included in the study

\begin{tabular}{|l|l|l|l|l|}
\cline { 2 - 5 } \multicolumn{1}{c|}{} & $\alpha$ & $\beta$ & $\gamma$ & $\delta$ \\
\hline Geographical location & South & North & Center & South \\
\hline Municipal level & $\checkmark$ & $\checkmark$ & $\checkmark$ & $\checkmark$ \\
\hline $\begin{array}{l}\text { Organizational model } \\
\text { (activities directly managed by the BDA) }\end{array}$ & & & & \\
\hline Awareness and promotion & & & & \\
\hline Recruitment and retention & & & & \\
\hline Blood collection & & $\checkmark$ & $\checkmark$ & \\
\hline Members & 4.352 & 5.797 & 5.245 & 10.460 \\
\hline Bags collected by the BDA & 6.522 & 3.527 & 5.169 & 15.284 \\
\hline Of which were plasma & 434 & - & 330 & 3.703 \\
\hline Bags collected by the public run BCA of reference & 1.093 & 7.947 & 286 & - \\
\hline
\end{tabular}

\section{Stage II - Data collection}

The data collection process included a range of qualitative and quantitative research methods, aimed at fulfilling different purposes.

\section{Focus group}

The identification of the impacts perceived by BDA members was achieved through a focus group, which stimulated an open debate among 9 key informants who shared the common characteristic of being both blood donors and volunteers for Avis. The selection of key informants followed the criteria of representativeness in terms of gender and geographical location of their BDA (Table 4). In all, $67 \%$ of the informants were aged between $26-35$ years old and the remaining 33\% between 36-45 years old.

Table 4: Profile of key informants who participated in the focus group

\begin{tabular}{|l|l|l|}
\hline Location & $\begin{array}{l}\text { Distribution of Italian } \\
\text { Avis members }\end{array}$ & $\begin{array}{l}\text { Individual } \\
\text { participants }\end{array}$ \\
\hline
\end{tabular}




\begin{tabular}{|c|c|c|c|c|c|}
\hline \multirow{2}{*}{ North } & \multirow{2}{*}{$60 \%$} & \multirow[b]{2}{*}{5} & $M$ & $67 \%$ & 3 \\
\hline & & & $F$ & $33 \%$ & 2 \\
\hline \multirow{2}{*}{ Center } & \multirow[b]{2}{*}{$19 \%$} & \multirow[b]{2}{*}{2} & $\mathrm{M}$ & $66 \%$ & 1 \\
\hline & & & $F$ & $34 \%$ & 1 \\
\hline \multirow[b]{2}{*}{ South } & \multirow{2}{*}{$21 \%$} & \multirow{2}{*}{2} & $\mathrm{M}$ & $66 \%$ & 1 \\
\hline & & & $\mathrm{F}$ & $34 \%$ & 1 \\
\hline
\end{tabular}

The focus group, led by one of the authors with the assistance of a National Avis employee, aligned with the well-established Donaldson's approach to theory-driven evaluation (Donaldson, 2007). The protocol followed mainly served as a guide to elicit stakeholders' view about the outcomes respectively yielded by being a blood donor member of Avis and by volunteering for this BDA. The evidence gathered has been used to test the plausibility and exhaustiveness of the preliminary program theory derived from consulting experts and from the systematic literature review described. In doing so, this modelling effort fits within a post-positivist position and conforms to a theoretical approach (Braun and Clarke, 2006), since the collection and analysis of evidence have been oriented by preconceived thematic categories stemming from researchers' tacit knowledge. The focus group has been audio-recorded, transcribed verbatim and the evidence gathered analysed by the two authors. This resulted in a further validation of the areas of impacts to be included in the quantitative analysis, which are as follows. Early diagnosis of undetected diseases: the assessment of blood donor eligibility may allow the detection of some diseases (such as Diabetes Mellitus type II, Hypercholesterolemia and Hereditary Hemochromatosis), enabling the selection of the most suitable countermeasures to halt or to slow down their natural progression.

Adoption of a healthier lifestyle: donors or volunteers may engage in health-conscious behavior (in terms of nutrition, physical activity, smoking, sexual behaviors, substance and alcohol consumption) because they belong to a TSO that promotes certain values and lifestyles. 
Personal satisfaction: in accordance with the widely recognized assumption that giving may be emotionally rewarding (Clary et al., 1998; Gillespie and Hillyer, 2002; Nilsson Sojka and Sojka, 2003; Evans and Ferguson, 2014), individual may gain returns from the fulfillment of an act of altruism.

Social capital: as some authors have pointed out (Guiddi et al., 2015; Alfieri et al., 2016; Bani and Strepparava, 2011), the very opportunity of establishing relationships while donating or volunteering can represent a benefit pursued by the individuals who take part in the networks flourishing within BDAs. The concept is here intended as "the sum of the actual and potential resources embedded within, available through, and derived from the network of relationships possessed by an individual or social unit. Social capital thus comprises both the network and the assets that may be mobilized through that network" (Nahapiet and Ghoshal 1998, p. 243).Human capital: as the literature on the 'willingness to give' points out (Clary et al., 1998; Guiddi et al., 2015; Alfieri et al., 2016), the acquisition of knowledge, competences and soft skills - in this case, through the participation in trainings activities offered by Avis - may foster the personal and professional growth of those involved.

Reinforcement of a 'giving culture': finally, the individual's experience as an Avis member may result in a higher propensity to make charitable contributions or to further volunteer, to the benefit of other TSOs.

\section{Review and reclassification of balance sheets}

A key component in the calculation of SROI is the identification of the total amount of resources necessary for the implementation of BDAs' activities (the total "inputs"). To do so, a proper allocation of costs incurred in the following areas is needed:

retention/recruitment; awareness/promotion; training (public or internal audience); donors' acceptance; eligibility assessment; sample taking; post-donation services (e.g. 
refreshment, periodic health checks); conservation and storage of the collected bags; transportation to Blood Centers. All these costs related to 2014 were, in turn, categorized as: consumables, equipment, human resources, and buildings. With the help of a National Avis employee, a review and reclassification of all balance sheets was performed to fit budgetary records to a standard framework of analysis.

\section{Survey}

Benefits were assessed through a self-reported online survey, autonomously administered by each unit and addressed to both members and unassociated donors (i.e., individuals who, even though they are not members of a BDA, go to a unit to donate blood). For the former group, the link to access the survey has been sent through email to all members for whom an email address was available. To further reinforce coverage, blood donors who visited the units in the period during which the survey was active were further solicited to complete it by appointed staff members. For the latter group, since BDAs do not retain contact information, only the second approach has been adopted.

The survey was open between March and July 2016 and divided into two main sections. The first section focused on the profiles of the respondents, the frequency and content of their donation/volunteering activity; the second on their perceptions of any perceived variation, for each area of impact, in terms of experienced change and relative attribution effect (a building block of the SROI method, representing the share of change that respondents ascribe to the fact they are BDA members or, conversely, unassociated blood donors). The second section also asked respondents about the indirect costs they incurred to engage in giving (i.e. travel costs, and the opportunity cost of the time spent donating/volunteering). All questions in the survey related to the donation experience in 2014, to be consistent with the research design.

\section{Ethics and data reliability}


The authors took all precautions to ensure the proper treatment of sensitive data. An Informed Consent form was included in the online survey, explaining the rationale of the research and the intended use of the gathered data. No identifying information was collected to ensure the anonymity of responses. Data were collected online through the survey platform Qualtrics and managed by the research team alone. Data were shared for publications and academic purposes only in aggregate form.

\section{Stage III - Data analysis}

Activity-based costing and assignment of a monetary value to non-monetized inputs Following the reclassification of balance sheets described above, for each category of inputs, both accounted costs and non-monetized inputs were considered (Nicholls et al., 2012) to estimate the full cost of service provision. Accordingly, the authors estimated the value of a set of resources as:

- Contributions in kind and/or advertising, referring to the concession of materials, equipment or public visibility occurring at no charge or at a subsidized price;

- Buildings, frequently granted for free (approximated by the rent per square meter by type of property and geographical location provided by the Real Estate Market Observatory of the Italian Revenue Agency);

- Productivity of unpaid volunteers, estimated through the adoption of a "replacement cost approach" (ILO 2011, p. 36). The estimation referred to the hourly salary volunteers would have received according to the minimum contractual level established by the National Collective Labour Contracts, widely adopted within BDAs. Conversely, when more appropriate (e.g. for external professionals), it considered the wages recorded for the year 2014 according to the national equivalent of the European NACE coding. 
Application of proxies to survey results

A monetization process was applied to establish the proper financial proxies aimed at highlighting the economic fallouts of the activities managed by Avis. After mapping the impacts that may be deemed "material", i.e. relevant to the perception of key informants (Nicholls et al., 2012), the researchers performed a further extensive literature review to identify some robust estimates of the economic repercussions of the activities carried out by BDAs (further details are provided in the Appendix).

\section{Application of SROI formula}

After collecting both measures of inputs and benefits in a comparable fashion, the authors calculated the SROI ratios. The following section reports the findings for each area of impact.

\section{THE POSITIVE IMPACT OF AVIS ON THE HEALTH AND WELLBEING OF MEMBERS}

This section reports the findings obtained through the survey submitted to the members of the four units included in this pilot study. A total of 1,564 respondents participated in the survey: 1,023 responses from Avis members (Table 5) and 43 responses from unassociated donors were deemed valid. Nearly 500 survey responses were discarded because either the questionnaires were not filled out completely or respondents declared not to be blood donors or volunteers in 2014 . The samples of respondents are representative of the overall population of members of each unit, whereas for the subsamples of unassociated donors, the population size and characteristics are unknown to BDAs, hindering any appraisal of their degree of representativeness. 
Table 5: Size and representativeness of samples $(\varepsilon=0.07)$

\begin{tabular}{lllll}
\hline & $\boldsymbol{\alpha}$ & $\boldsymbol{\beta}$ & $\mathbf{Y}$ & $\boldsymbol{\delta}$ \\
\hline Level of confidence & $95 \%$ & $99 \%$ & $90 \%$ & $95 \%$ \\
\hline Sample size required & 188 & 321 & 134 & 192 \\
\hline Valid compilations by members & 188 & 469 & 158 & 208 \\
\hline
\end{tabular}

The analysis always resulted in positive ratios (Figure 2), varying in a range between $€ 1.70$ and $€ 13.80$. In other words, each euro invested by unit $\alpha$ generates a value calculated as $€ 1.70$, while each euro invested by unit $\beta$ generates a value of $€ 13.80$. Findings are reported below for each area of impact.

\section{[Figure 2 - The SROI ratios]}

Area of Impact 1: Early diagnosis of undetected diseases

Except for unit $\beta$, the incidence of this area of impact is negligible. The underlying factors explaining such an outcome relate to the relatively higher dissemination among its donors of Hereditary Hemochromatosis, in line with the epidemiology of this disease, which is much more widespread in the northern areas of Italy and Europe (Velati et al., 2003).

Area of Impact 2: Adoption of a healthier lifestyle

By far the most significant area of impact is in the ability to solicit the adoption of a healthier lifestyle or, conversely, the abandonment of detrimental behaviors. Benefits may be divided into six sub-areas (Table 6).

Table 6: Adoption of a healthier lifestyle 


\begin{tabular}{|c|c|c|}
\hline & $\begin{array}{l}\text { Mean - } \\
\text { BDA } \\
\text { members } \\
(n=1,023)\end{array}$ & $\begin{array}{l}\text { Mean - } \\
\text { Unassociated } \\
\text { donors } \\
(n=43)\end{array}$ \\
\hline \multicolumn{3}{|l|}{ Nutrition } \\
\hline Individuals who would have needed support from a specialist & $7,10 \%$ & $11,70 \%$ \\
\hline Per capita prevented need for visits & 3,0 & 2,3 \\
\hline Attribution effect & $56,80 \%$ & $45,50 \%$ \\
\hline \multicolumn{3}{|l|}{ Physical activity } \\
\hline \multicolumn{3}{|l|}{ Individuals } \\
\hline who increased physical activity & $26,20 \%$ & $16,40 \%$ \\
\hline over 40 who increased physical activity & $18,40 \%$ & $9,00 \%$ \\
\hline over 40 who improved BMI or level of physical activity & $8,90 \%$ & $4,20 \%$ \\
\hline Attribution effect & $29,20 \%$ & $26,70 \%$ \\
\hline \multicolumn{3}{|l|}{ Smoking } \\
\hline Incidence of smokers (past and present) & $42,30 \%$ & $50,70 \%$ \\
\hline \multicolumn{3}{|l|}{ Individuals } \\
\hline who reduced smoking & $6,30 \%$ & $10,00 \%$ \\
\hline who quit smoking & $24,00 \%$ & $21,60 \%$ \\
\hline Attribution effect & $24,70 \%$ & $26,50 \%$ \\
\hline \multicolumn{3}{|l|}{ Substance consumption } \\
\hline Individuals who quit substance consumption & $4,90 \%$ & $11,80 \%$ \\
\hline Attribution effect & $35,00 \%$ & $49,20 \%$ \\
\hline \multicolumn{3}{|l|}{ Sexual behavior at risk } \\
\hline Individuals who have abandoned risky behaviors & $78,20 \%$ & $88,10 \%$ \\
\hline Attribution effect & $38,10 \%$ & $41,50 \%$ \\
\hline \multicolumn{3}{|l|}{ Alcohol consumption } \\
\hline \multicolumn{3}{|l|}{ Individuals } \\
\hline who reduced consumption & $21,20 \%$ & $16,00 \%$ \\
\hline with previous habitually excessive consumption & $4,10 \%$ & $2,80 \%$ \\
\hline who quit habitually excessive consumption & $1,30 \%$ & $0,00 \%$ \\
\hline Attribution effect & $37,10 \%$ & $38,70 \%$ \\
\hline
\end{tabular}

These benefits can be grouped into three blocks, according to the average level of adoption of healthy behaviors and attribution effect respectively reported by the two subsamples. The first block includes improved nutrition and increased physical activity: BDA members show a wider adoption of healthy behaviors compared to unassociated donors. Also, being a BDA member seems to play a greater role in the modification of their behaviors compared to the changes that unassociated donors ascribe to simply being blood donors. The second includes smoking, drug consumption and risky sexual behavior. In this case, members present a lesser prior incidence of detrimental behaviors, but also a 
lower attribution of the positive change experienced to their BDA membership when compared to unassociated donors. The third block includes alcohol consumption: here, members show a wider adoption of detrimental behaviors and are less prone to attribute any improvement to the fact that they are BDA members compared to unassociated donors.

Area of Impact 3: Personal satisfaction

When asked about their willingness to pay (WTP) to continue donating or volunteering, most respondents declared themselves unwilling, conceiving these acts as free by nature. A relatively larger share of unassociated donors declared themselves unwilling to pay because the blood donation they have made already represents a sufficient contribution. Moreover, $22,3 \%$ of Avis donors and $25,5 \%$ of unassociated donors declared themselves willing to pay if it is indispensable to helping a needy person. The respondents who emphasized the sense of fulfillment derived from these gestures represented a small proportion, though it was relatively higher among Avis donors.

[Figure 3 - Respondents who are willing or unwilling to pay to donate or volunteer]

Moreover, to express in monetary terms the value indirectly attributed to blood donation, the average WTP - complemented by the travel expenses incurred by individuals who go to donate and by the opportunity cost of the time they devote to donation - returns figures of $€ 17.85$ and $€ 17.76$, respectively, for donors who are associated or unassociated (Table 7).

Table 7: The value attributed to giving 


\begin{tabular}{lll}
\hline & $\begin{array}{l}\text { Mean - } \\
\text { BDA active donors } \\
(\mathbf{n = 9 2 9})\end{array}$ & $\begin{array}{l}\text { Mean - } \\
\text { Unassociated donors } \\
(\mathbf{n}=\mathbf{4 3})\end{array}$ \\
\hline WTP of those who are willing to pay & $€ 15,65$ & $€ 13,96$ \\
WTP (average) & $€ 4,19$ & $€ 3,37$ \\
Value attributed to the experience & $€ 17,85$ & $€ 17,76$ \\
\hline
\end{tabular}

\section{Area of Impact 4: Social capital}

In focusing on the crucial function carried out by BDAs in promoting a higher level of social cohesion within the community, data shows a clear distinction between members and unassociated donors. For the former group, the frequency and intensity of participation in social gatherings and the opportunity to establish relevant and durable relationships during the donation experience represent a significant effect (Table 8).

Table 8: Social capital

\begin{tabular}{lll}
\hline & $\begin{array}{l}\text { Mean - } \\
\text { BDA }\end{array}$ & $\begin{array}{l}\text { Mean - } \\
\text { Unassociated } \\
\text { donors } \\
\text { (n= 43) }\end{array}$ \\
\hline Individuals who attended social gatherings & $\begin{array}{l}\text { members } \\
(\mathbf{n = 1 , 0 2 3 )}\end{array}$ & $0,0 \%$ \\
Per capita annual events attended & $14,4 \%$ & 0 \\
Per capita annual hour dedicated & 3 & 0 \\
Individuals who established relationships & 10,1 & $12,8 \%$ \\
Per capita relationships established & $30,0 \%$ & 0,4 \\
Per capita weekly hours dedicated & 5,1 & 0,5 \\
\hline
\end{tabular}

\section{Area of Impact 5: Human capital}

Equally relevant are the impacts generated through the provision of training initiatives aimed at promoting the professional and personal growth of volunteers (Table 9). Although the average share of volunteers engaged in similar activities is about $43 \%$, most of them recognize that this experience not only enhances their knowledge and skills, but also plays a role in their attempts to obtain their current job (respectively an average of $68 \%$ and $60 \%)$. 
Table 9: Human capital

\begin{tabular}{cl}
\hline & $\begin{array}{l}\text { Mean - } \\
\text { BDA } \\
\text { volunteers } \\
(\mathbf{n}=\mathbf{5 2})\end{array}$ \\
\hline $\begin{array}{l}\text { Volunteers who declared that } \\
\text { they attended trainings and formative courses } \\
\text { the experience increased their level of knowledge }\end{array}$ & $43 \%$ \\
the experience facilitated the obtainment of their job & $68 \%$ \\
Attribution effect - job obtainment & $60 \%$ \\
Attribution effect - salary increase & $41 \%$ \\
\hline
\end{tabular}

Area of Impact 6: Reinforcement of a 'giving culture'

Finally, Avis members show a higher propensity to give or to further volunteer to the benefit of other TSOs (

Table 10). Respondents declare that the previous experience significantly explains (32\%) the fact that they engaged as volunteers for other TSOs, and their monetary giving in favor of other charities (23\%). Conversely, unassociated donors mainly recognize $(31 \%)$ the effect of their blood donation experience as a cause of their inclination to give money to TSOs, whereas they scarcely attribute (9\%) their act of volunteering to the fact that they are blood donors.

Table 10: Reinforcement of a 'giving culture'

\begin{tabular}{|c|c|c|}
\hline & $\begin{array}{l}\text { Mean - } \\
\text { BDA } \\
\text { members } \\
(n=1,023)\end{array}$ & $\begin{array}{l}\text { Mean - } \\
\text { Unassociated } \\
\text { donors } \\
(n=43)\end{array}$ \\
\hline \multicolumn{3}{|l|}{ Individuals who } \\
\hline give money to other TSOs & $27 \%$ & $29 \%$ \\
\hline
\end{tabular}




\begin{tabular}{lll}
\hline \multicolumn{1}{c}{ volunteer within other TSOs } & $15 \%$ & $4 \%$ \\
Attribution effect (monetary giving) & $23 \%$ & $32 \%$ \\
Attribution effect (volunteering) & $32 \%$ & $9 \%$ \\
Average annual donations (€) & 167.80 & 165.17 \\
Per capital annual hours spent in volunteering & 196 & 88 \\
\hline
\end{tabular}

\section{DISCUSSION AND LESSONS LEARNED}

Based on the study findings, this section discusses the contributions to the advancement of knowledge and give suggestions for further research. Moreover, it outlines the managerial and policy implications of the study and discloses its limitations and lessons learned.

\section{Contribution to knowledge and research development}

This study responds to the research question by underlining the role of BDAs in generating beneficial social and health impacts for their members. This opens up a multifaceted advancement of the extant knowledge and research.

First, although the benefits pursued through blood donation have previously been analyzed and reported (Gillespie and Hillyer, 2002; Masser et al., 2008; Bednall et al., 2013; Ferguson, 2015), this study sought to quantify them by calculating the actual socioeconomic value of BDAs' activities. This can contribute to the health economics literature, too often focused on specific aspects of the blood supply chain (Sarov et al., 2007; Fischinger et al., 2010) neglecting the assessment of the overall blood donation experience and the role played by BDAs in the generation of value to the benefit of their members.

Second, findings enrich the literature on blood donors' motivating factors (Nilsson Sojka and Sojka, 2003; Bani and Strepparava, 2011; Evans and Ferguson, 2014; Guiddi et al., 2015; Alfieri et al. 2016). Indeed, the study goes well beyond an exclusive assessment of 
the "hard" impacts of blood donation (the health-related ones), which typically are "easier to measure or subject to more established means of measurement" (Nicholls et al. 2012, p. 34). Conversely, it develops fresh scientific knowledge by collecting primary data to appraise, also in economic terms, the magnitude of the "soft" impacts related to blood donation and volunteering, for which a well-established evidence base is still missing. Therefore, it sheds light on substantial although frequently neglected socio-economic repercussions accruing from the activities performed by BDAs (such as the creation of social and human capital or the reinforcement of a 'giving culture'). Third, the findings add further insights to the study of the strategic management of the BDAs' relationship with their members by making an original contribution to the body of literature, thus deepening the range of recruitment and retention strategies adoptable by BCAs and BDAs (Chliaoutakis et al., 1994; Hinrichs et al., 2008).

Evidence, in this respect, gives the opportunity to generalize these findings to a wider array of TSOs operating with similar organizational models and based on a sound contribution of volunteering work, although not necessarily strictly operating in the health sector. While these benefits are often intuitively recognized, the engagement in SIE allows TSOs to lead the managerial, cultural and political debate around their interventions to a higher level of sophistication and legitimacy.

From a methodological standpoint, this study fills a gap in the use of SROI. To date, a rather poor dissemination of SROI analyses is noticeable in the healthcare sector (Millar and Hall, 2013; Banke-Thomas et al., 2015) and even poorer in relation to the Italian Third Sector. The innovative nature of this study lies in the adoption of this methodology to investigate hitherto little-explored interventions. This is even more relevant if we consider the significant lack of SROI or CBA analyses explicitly designed to assess the impact of BDAs' activities. 
Furthermore, the methodology applied has confirmed its ability to provide fruitful analyses of costs and benefits, while strongly fostering the involvement of stakeholders in such processes (Arvidson et al., 2010; Arvidson et al., 2013; Simsa et al., 2014). This result adds to the literature on SIE, where stakeholder engagement in evaluation practices is a highly debated topic in scientific and political contexts.

\section{Managerial and policy implications}

The study confirms the claims of a vast prior body of literature on SIE (Harlock, 2013; Millar and Hall, 2013; Maier et al., 2015) which has argued that one of the main advantages of SROI is its remarkable suitability to feed organizational learning purposes, coupled with effectiveness as a reporting tool. Indeed, the present analysis allowed identification of the strengths and weaknesses of BDAs' organizational models, while prompting the implementation of the corrective actions, which are possibly required to maximize their capacity to generate positive impacts.

On the one hand, the present findings enable recognition of the domains where BDAs should strengthen their interventions - smoking, drug consumption, risky sexual behaviors and, above all, alcohol consumption - in order to play a more significant role among all the alternative factors that can induce individuals to adopt healthier behavioral models. In this instance, SIE can substantially enhance the effectiveness of BDAs' recruiting and retention strategies, allowing to systematically track the results achieved - annually and, potentially, over time - in each area of impact and to refine the actions implemented accordingly.

On the other hand, this SROI analysis also supports the accountability efforts made by BDAs to properly communicate how they provide incremental positive impacts to their stakeholders (i.e. the generation of social and human capital, or the reinforcement of a 'giving culture'). Furthermore, the analysis provides preliminary evidence supporting the hypothesis that the resources invested to finance BDAs' operations contribute to the 
generation of a considerable social value. The ratios systematically assumed a positive (variable) value. In other words, at least at first glance, BDAs' interventions appear to be deserving of financial and material support because they generate positive impacts for their members, and are therefore desirable from the perspective of the public funder. Although this pilot research engaged a small sample of units, the robustness of the results and the plausibility of their variability find a benchmark in the prior study by Banke-Thomas et al. (2015).

\section{Limitations}

Despite the study contributes to the development of the literature, some limitations affect the generalizability of its findings.

First, an annual retrospective SROI was calculated, thus avoiding assumptions and forecasts about the "drop-off effect" affecting impacts (Nicholls et al., 2012). However, the effect of this limitation was partially softened by the use of proxies representing life-time costs: this approach led to the need for a traceability system (compatible with anonymity requirements) in order to avoid the overestimation of impacts due to a "double counting" of the same benefit for the same respondent (Nicholls et al., 2012).

Second, the engagement of a restricted pool of units partially undermines the generalizability of the evidence gathered, and suggests the need for a perspective extension of the sample. However, the application of this analytical framework to different organizational models may have a detrimental effect on data collection: in fact, the activities considered for the SROI analysis are often managed by several BDAs at the municipal level that interface with a single unit only in charge of blood collection. This creates a need to retrieve information dispersed across a multiplicity of organizations, making data collection a lot more burdensome while enabling a comparative analysis with publicly-run agencies. 
Third, the survey only reached a limited sample of unassociated donors. An enlargement of this control group would allow a more rigorous isolation of the impacts directly attributable to membership in BDAs. This limit, often identified as a major weakness of SROI analyses (Banke-Thomas et al. 2015), might be overcome through the inclusion in the sample of publicly-run BCAs, where they are much more likely to go to donate.

\section{Lessons learned}

The effort of running such an evaluation is massive. The authors' reflections are here translated into suggestions for follow-ups or similar research efforts in other contexts.

In primis, the stage of cost analysis often results in a fatiguing effort of adaptation of ordinary accountability to classifying expenditures according to specific purposes. Moreover, especially within small TSOs, the relative scarcity of economic and human resources allocated to SIE makes the attempt to collect all relevant data for the valorization of non-monetized inputs from scratch even less sustainable. These practical constraints usually lead to SIE conceived as a disturbing factor that diverts TSO employees from their core tasks and targets. The engagement of key stakeholders in the research idea and design is then fundamental to ensure a higher commitment during the whole process.

In secundis, the value of such evaluation effort could be amplified by complementing a SROI analysis with a comparative study on unassociated donors and, more relevant, with similar services supplied by publicly-run BCAs. This would complement the research findings allowing considerations more robust on the benefits of BDAs activities to public sector budgets too.

Finally, due to the high learning potential of SIEs in the strategic management of TSOs, a long and resource-intensive study would give its best in helping the organization's planning 
capacity, embedding the evaluation process into strategy since the first steps. For example, considering a preliminary SROI esteem (ex-ante, rather than ex-post) would help steering the organization towards pursuing its mission.

\section{CONCLUSIONS}

Despite the various caveats set out above, the potential for replication of this study is high due to the specific nature of the selected method. SIE is expensive and extremely "resource intensive" (Maier et al., 2015, p. 1820), but the learnings from such an analysis can be extremely valuable whenever run in a rigorous way. This research aims at providing renewed impetus to the scientific discussion and the cross-fertilization of practices in the field of SIE, an issue that will further grow in salience within the academic, political and cultural debates in Italy and worldwide.

\section{ACKNOWLEDGMENTS}

The authors would like to thank all the National Avis staff involved in this research project in the research design and implementation stages, particularly President Vincenzo Saturni. Special thanks also go to the municipal-level units of Avis that actively participated in the study as well as to their members, whose contribution was essential in the data collection.

\section{FUNDING AND CONFLICT OF INTEREST}

While the research study was partially funded by Avis, we have no conflicts of interest to disclose regarding this paper, representing a research product entirely drafted by the authors. 


\section{REFERENCES}

1. Alfieri, S., Guiddi, P., Marta, E., Saturni, V., 2016. Economic crisis and blood donation: How are donors' motivations changing?. Transfusion and Apheresis Science. 54(3), 396-400.

2. Arvidson, M., Lyon, F., McKay, S., Moro, D., 2010. The ambitions and challenges of SROI. Third Sector Research Centre. Working Paper 49. University of Birmingham.

3. Arvidson, M., Lyon, F., McKay, S., Moro, D., 2013. Valuing the social? The nature and controversies of measuring social return on investment (SROI). Voluntary Sector Review. 4(1), 3-18.

4. Atsma, F., Veldhuizen, I., Verbeek, A., de Kort, W., de Vegt, F., 2011. Healthy donor effect: its magnitude in health research among blood donors. Transfusion. 51(8), 1820-1828.

5. Banca d'Italia, 2015. I bilanci delle famiglie italiane nell'anno 2014, n. 64. Available on-line: www.bancaditalia.it/pubblicazioni/indagine-famiglie/bilfam2014/suppl 64 15.pdf

6. Banke-Thomas, A.O., Madaj, B., Charles, A., van den Broek, N., 2015. Social Return on Investment (SROI) methodology to account for value for money of public health interventions: a systematic review. BMC public health. 15, 582.

7. Bani, M., Strepparava, M.G., 2011. Motivation in Italian whole blood donors and the role of commitment. Psychology, health \& medicine. 16(6), 641-649.

8. Barton, J.C., Barton, J.C., Acton, R.T., So, J., Chan, S., Adams, P.C., 2012. Increased Risk of Death From Iron Overload Among 422 Treated Probands With HFE Hemochromatosis and Serum Levels of Ferritin Greater Than $1000 \mu \mathrm{g} / \mathrm{L}$ at Diagnosis. Clinical Gastroenterology and Hepatology. 10, 412-416.

9. Bednall, T.C., Bove, L.L., Cheetham, A., Murray, A.L., 2013. A systematic review and meta-analysis of antecedents of blood donation behavior and intentions. Social Science \& Medicine. 96, 86-94.

10. Boenigk, S., Leipnitz, S., Scherhag, C., 2011. Altruistic values, satisfaction and loyalty among first-time blood donors. International Journal of Nonprofit and Voluntary Sector Marketing. 16(4), 356-370.

11.Braun, V., Clarke, V., 2006. Using thematic analysis in psychology. Qualitative research in psychology. 3(2), 77-101.

12. Bufali, M.V., Fiorentini, G., Calò, F., 2017. Introduzione, in: Saturni, V., Fiorentini, G., Ricciuti, E. (Eds.), La VIS di AVIS. La valutazione dell'impatto economico e sociale dell'Associazione Volontari Italiani del Sangue. FrancoAngeli editore, Milano, pp. 25-56.

13. Caputo, S., Lauro, R., Nicolucci, A., 2013. Facts and figures about diabetes in Italy. Italian Diabetes Monitor. Fondazione Mario Negri Sud.

14. Cavazza, M., Jommi, C., 2013. La raccolta di plasma ed il sistema di emocomponenti ed emoderivati in Italia. Egea, Milano.

15. Chliaoutakis, J., Trakas, D. J., Socrataki, F., Lemonidou, C., Papaioannou, D., 1994. Blood donor behaviour in Greece: implications for health policy. Social Science \& Medicine. 38(10), 1461-1467.

16. Clary, E.G., Snyder, M., Ridge, R.D., Copeland, J., Stukas, A.A., Haugen, J., Miene, P., 1998. Understanding and assessing the motivations of volunteers: a functional approach. Journal of personality and social psychology. 74(6), 1516.

17. Cohen, S., Lichtenstein, E., Prochaska, J.O., Rossi, J.S., Gritz, E.R., Carr, C.R., ... Ossip-Klein, D., 1989. Debunking myths about self-quitting: Evidence from 10 prospective studies of persons who attempt to quit smoking by themselves. American Psychologist. 44(11), 1355. 
18. Cordes, J.J., 2016. Using cost-benefit analysis and social return on investment to evaluate the impact of social enterprise: Promises, implementation, and limitations. Evaluation and Program Planning. 64(2016): 98-104.

19. Delea, T.E., Sofrygin, O., Thomas, S.K., Baladi, J.F., Phatak, P. D., Coates, T.D., 2007. Cost effectiveness of once-daily oral chelation therapy with Deferasirox versus infusional Deferoxamine in Transfusion-dependent Thalassaemia patients. Pharmacoeconomics. 25(4), 329-342.

20. Donaldson, S.I., 2007. Program theory-driven evaluation science: Strategies and applications. Taylor and Francis Group, New York.

21. DPA (Dipartimento Politiche Antidroga), 2014. Relazione Annuale al Parlamento 2014. Uso di sostanze stupefacenti e tossicodipendenze in Italia. Dati relativi all'anno 2013 e primo semestre 2014 - elaborazioni 2014.

22.Drummond, M.F., Sculpher, M.J., Claxton, K., Stoddart, G.L., Torrance, G.W., 2015. Methods for the economic evaluation of health care programmes. Oxford university press.

23. Emerson, J., Cabaj, M., 2000. Social Return on Investment. Making Waves.11, 104.

24. Evans, R., Ferguson, E., 2014. Defining and measuring blood donor altruism: a theoretical approach from biology, economics and psychology. Vox sanguinis. 106(2), 118-126.

25. Falco, V., Corsaro, L., 2014. Italian Diabetes Monitor. Analysis of the Diabetes in Italy. 1st Year - July-September $2014-\mathrm{N}^{\circ} 2$. Medi-Pragma.

26. Fattore, G., Torbica, A., Susi, A., Aguzzi, G., Benelli, G., Gozzo, M., Toso, V., 2012. The social and economic burden of stroke survivors in Italy: a prospective, incidence-based, multi-centre cost of illness study. BMC Neurology. 12(1), 137.

27. Ferguson, E., 2015. Mechanism of altruism approach to blood donor recruitment and retention: a review and future directions. Transfusion Medicine. 25(4), 211-226.

28. Fischinger, J.M., Stephan, B., Wasserscheid, K., Eichler, H., Gärtner, B.C., 2010. A cost-benefit analysis of blood donor vaccination as an alternative to additional DNA testing for reducing transfusion transmission of hepatitis B virus. Vaccine. 28(49), 7797-7802.

29. Gallerani, M., Volpato, S., Cellini, M., Reverberi, R., Mikhailidis, D.P., Manfredini, R., 2014. Risk of illness, hospitalization and death in a cohort of blood donors in Italy. Current Medical Research \& Opinion. 30(9), 1803-1812.

30. Genovese, S., 2009. Diabete: impariamo ad affrontarlo. Informazioni utili. O.N.Da, Milano. Available on-line: www.ondaosservatorio.it/ondauploads/2014/11/diabete.pdf

31. Gillespie, T.W., Hillyer, C.D., 2002. Blood donors and factors impacting the blood donation decision. Transfusion Medicine Reviews. 16(2), 115-130.

32. Glover, D., Henderson, J., 2010. Quantifying Health Impacts of Government Policies: A How-to Guide to Quantifying the Health Impacts of Government Policies. Department of Health, London.

33. Grabowski, D.C., Lakdawalla, D.N., Goldman, D.P., Eber, M., Liu, L.Z., Abdelgawad, T., ... Philipson, T., 2012. The large social value resulting from use of statins warrants steps to improve adherence and broaden treatment. Health Affairs. 31(10), 2276-2285.

34. GU (Gazzetta Ufficiale), n.23 - Supplement n. 8, 28 January 2013.

35. Guiddi, P., Alfieri, S., Marta, E., Saturni, V., 2015. New donors, loyal donors, and regular donors: Which motivations sustain blood donation?. Transfusion and Apheresis Science. 52(3), 339-344. 
36. Harlock, J., 2013. Impact measurement practice in the UK third sector: a review of emerging evidence. Third Sector Research Centre. Working paper 106. University of Birmingham.

37. Healy, K., 2000. Embedded Altruism: Blood Collection Regimes and the European Union's Donor Population. American journal of sociology. 105(6), 1633-1657.

38. Hinrichs, A., Picker, S.M., Schneider, A., Lefering, R., Neugebauer, E.A.M., Gathof, B.S., 2008. Effect of blood donation on well-being of blood donors. Transfusion medicine. 18(1), 40-48.

39. Holman, R.R., Paul, S.K., Bethel, M.A., Neil, H.A.W., Matthews, D.R., 2008. Longterm follow-up after tight control of blood pressure in type 2 diabetes. New England Journal of Medicine. 359(15), 1565-1576.

40. lajya, V., Lacetera, N., Macis, M., Slonim, R., 2013. The effects of information, social and financial incentives on voluntary undirected blood donations: Evidence from a field experiment in Argentina. Social Science \& Medicine. 98, 214-223.

41. IHRSA, 2014. The 2014 IHRSA Global Report. The State of the Health Club Industry.

42. ILO, 2011. Manual on the measurement of volunteer work.

43. IRI, 2015. Point of View. Prezzi, promozioni ed accise. Quale impatto sul mercato della birra?

44. ISMEA, 2013. Available on-line: www.ismeaservizi.it/flex/cm/pages/ServeBLOB.php/L/IT/IDPagina/4051 (last accessed 24.09.15).

45. Istat, 2014a. II valore monetario dello stock di capitale umano in Italia - Anni 19982008.

46. Istat, 2014b. L'uso e l'abuso di alcol in Italia. Anni 2012-2013.

47. Istituto Superiore di Sanità, 2015,. Not Ist Super Sanità, 28(2): 3-47. Available online: www.iss.it/binary/publ/cont/ISTnuovo2.15.pdf

48. Jha, P., Ramasundarahettige, C., Landsman, V., Rostron, B., Thun, M., Anderson, R.N., ... Peto, R., 2013. 21st-century hazards of smoking and benefits of cessation in the United States. New England Journal of Medicine. 368(4), 341-350.

49. Karacan, E., Seval, G.C., Aktan, Z., Ayli, M., Palabiyikoglu, R., 2013. Blood donors and factors impacting the blood donation decision: motives for donating blood in Turkish sample. Transfusion and Apheresis Science. 49(3), 468-473.

50. Lee, S.J., Neumann, P.J., Churchill, W.H., Cannon, M.E., Weinstein, M.C., Johannesson, M., 1997. Patients' willingness to pay for autologous blood donation. Health Policy. 40(1), 1-12.

51. Leitman, S.F., 2013. Hemochromatosis: the new blood donor. ASH Education Program Book. 1, 645-650.

52. Maier, F., Simsa, R., Schober, C., Millner R., 2015. SROI as a Method for Evaluation Research: Understanding Merits and Limitations, VOLUNTAS: International Journal of Voluntary and Nonprofit Organizations. 26(5), 1805-1830.

53. Masser, B.M., White, K.M., Hyde, M.K., Terry, D.J., 2008. The Psychology of Blood Donation: Current Research and Future Directions. Transfusion Medicine Reviews. 22(3), 215-233.

54. Massmarket, 2015. Available on-line: www.massmarket.it/viniconf.htm (last accessed 18.09.2015).

55. Millar, R., Hall, K., 2013. Social return on investment (SROI) and performance measurement: The opportunities and barriers for social enterprises in health and social care. Public Management Review. 15(6), 923-941. 
56. Ministero della Salute, 2014. Relazione del Ministro della Salute al Parlamento sugli interventi realizzati ai sensi della Legge 30.3. 2001 n. 125. Legge Quadro in materia di alcol e problemi alcolcorrelati.

57. Nahapiet, J., Ghoshal, S., 1998. Social capital, intellectual capital, and the organizational advantage. Academy of Management Review. 23(2), 242-266.

58. Nicholls, J., Lawlor, E., Neitzert, E., Goodspeed, T., 2012. A Guide to Social Return on Investment, second edition. SROI Network, London.

59. Niederau, C., Fischer, R., Sonnenberg, A., Stremmel, W., Trampisch, H.J., Strohmeyer, G., 1985. Survival and causes of death in cirrhotic and in noncirrhotic patients with primary hemochromatosis. New England Journal of Medicine. 313(20), 1256-1262.

60. Nilsson Sojka, B., Sojka, P., 2003. The blood-donation experience: perceived physical, psychological and social impact of blood donation on the donor. Vox Sanguinis. 84(2), 120-128.

61. Ógáin, E., Lumley, T., Pritchard, D., 2012. Making an impact: Impact measurement among charities and social enterprises in the UK. New Philanthropy Capital, London.

62. OsMed, 2015. L'uso dei farmaci in Italia. Rapporto Nazionale 2014. Agenzia Italiana del Farmaco, Roma.

63. Roberts, R.D., Wolkoff, M.J., 1988. Improving the quality and quantity of whole blood supply: limits to voluntary arrangements. Journal of health politics, policy and law. 13(1), 167-178.

64. Rombout-Sestrienkova, E., Nieman, F.H.M., Essers, B.A.B., van Noord, P.A.H., Janssen, M.C.H., van Deursen C.T.B.N., ... Koek, G.H., 2012. Erythrocytapheresis versus phlebotomy in the initial treatment of HFE hemochromatosis patients: results from a randomized trial. Transfusion. 52(3): 470-477.

65. Sarov, B., Novack, L., Beer, N., Safi, J., Soliman, H., Pliskin, J.S., ... Shinar, E., 2007. Feasibility and cost-benefit of implementing pooled screening for HCVAg in small blood bank settings. Transfusion Medicine. 17(6), 479-487.

66. Shehu, E., Hofmann, A., Clement, M., Langmaack, A., 2015. Healthy donor effect and satisfaction with health. European Journal of Health Economics. 16(7), 733745.

67. SIMG (Società Italiana di Medicina Generale e delle Cure Primarie), 2014. VIII Report Health Search, Anno 2013-2014. SIMG, Firenze.

68. Simsa, R., Rauscher, O., Schober, C., Moder, C., 2014. Methodological Guideline For Impact Assessment. TSI Working Paper Series No. 1.

69. TNS Opinion \& Social, 2014. Special Eurobarometer 412. Sport and physical activity. Wave EB80.2. Brussels, Belgium: European Commission, Directorate General for Education and Culture.

70. Trotter, L., Vine, J., Leach, M., Fujiwara, D., 2014. Measuring the Social Impact of Community Investment: A Guide to using the Wellbeing Valuation Approach. HACT, London.

71. Velati, C., Marlianici, E., Rigamonti, D., Barillari, G., Chiavilli, F., Fugiani, P., ... Sampietro, M., 2003. Mutations of the hemochromatosis gene in Italian candidate blood donors with increased transferrin saturation. The Hematology Journal. 4(6), 436-440.

72. WHO (World Health Organization), 2014. Global status report on alcohol and health-2014.

73. Wiens, A., Lenzi, L., Venson, R., Pedroso, M. L., Correr, C.J., Pontarolo, R., 2013. Economic evaluation of treatments for chronic hepatitis $B$. Brazilian Journal of Infectious Diseases.17(4), 418-26. 
74. Williams, R., Van Gaal, L., Lucioni, C., 2002. Assessing the impact of complications on the costs of Type II diabetes. Diabetologia. 45(7), S13-S17.

75. Yang, M.C., Fann, C.Y., Wen, C.P., Cheng, T.Y., 2005. Smoking attributable medical expenditures, years of potential life lost, and the cost of premature death in Taiwan. Tobacco Control. 14(suppl 1), i62-i70. 